\section{BMJ Open Respiratory Research}

\title{
Environmental impact of inhalers for respiratory diseases: decreasing the carbon footprint while preserving patient-tailored treatment
}

\author{
Sara Panigone, ${ }^{1}$ Federica Sandri, ${ }^{1}$ Rossella Ferri, ${ }^{2}$ Andrea Volpato, ${ }^{2}$ Elena Nudo, ${ }^{3}$ \\ Gabriele Nicolini ${ }^{3}$
}

To cite: Panigone $\mathrm{S}$, Sandri F, Ferri R, et al. Environmental impact of inhalers for respiratory diseases: decreasing the carbon footprint while preserving patient-tailored treatment. BMJ Open Resp Res 2020;7:e000571. doi:10.1136/ bmjresp-2020-000571

Received 30 January 2020 Revised 18 March 2020 Accepted 18 March 2020
Check for updates

(c) Author(s) (or their employer(s)) 2020. Re-use permitted under CC BY-NC. No commercial re-use. See rights and permissions. Published by BMJ.

${ }^{1}$ Corporate Marketing, Chiesi Farmaceutici SpA, Parma, Italy

${ }^{2}$ Corporate Health Safety

\& Environment, Chiesi Farmaceutici SpA, Parma, Italy

${ }^{3}$ Global Medical Affairs, Chiesi Farmaceutici SpA, Parma, Italy

Correspondence to Dr Sara Panigone; s.panigone@chiesi.com

\section{ABSTRACT}

Patients with asthma and Chronic Obstructive Respiratory Disease (COPD) rely on three main device classes for inhalation therapy: metered-dose inhalers (MDIs), dry powder inhalers (DPIs) and soft-mist inhalers (SMls). The carbon footprint (CF) of these inhalers differs with MDIs having a higher impact than DPIs and SMls due to the propellant in MDIs. However, the certified CF of specific MDI products may differ significantly. MDIs still represent an essential option for many patients. Consequently, novel approaches shall be considered to balance environmental goals with patient health and well-being while maintaining a diverse range of choices for patients and physicians.

\section{INTRODUCTION}

Metered-dose inhalers (MDIs) and dry powder inhalers (DPIs) are the most commonly used devices for inhaled drug delivery in the treatment of asthma and COPD. Soft-mist inhalers (SMIs) are also used in the treatment of COPD and to a lesser extent in asthma. MDIs contain propellants, liquified gases providing the force to generate the aerosol cloud. Until early 1990s, MDIs contained chlorofluorocarbon (CFC) propellants, which were ozonedepleting substances and were therefore phased out under the Montreal Protocol. Pharmaceutical companies developed CFCfree MDIs, to ensure a seamless transition for patients, replacing CFC with hydrofluoroalkane (HFA) propellants: HFA134a and HFA227ea, which are not ozone-depleting and have a lower global warming potential (GWP). ${ }^{1}$

In 2016, the Parties to the Montreal Protocol adopted the Kigali Amendment, centred on the phase-down of hydrofluorocarbons (HFC), aimed at encouraging use of low GWP alternatives, where they exist and are available, across several industrial sectors (eg, in air conditioning systems). The HFCs include HFA propellants for MDIs, despite accounting for $0.048 \%$ of the total greenhouse gases emissions. ${ }^{23}$ Indeed, the EU regulation No 517/2014 recognises an exemption for HFA propellants for pharmaceutical use until an alternative low GWP fluorocarbon can be identified.

Environmental impact, measured as the carbon footprint $(\mathrm{CF})$, is different for every specific product and proper quantification is needed to assess current impact. This study aimed at quantifying the $\mathrm{CF}$ of specific products using an innovative approach, as well as estimating the $\mathrm{CF}$ of the same products when manufactured with the new low GWP propellant HFA152a.

\section{METHODS}

Calculation of the CF of the products has been performed considering the whole product lifecycle. We developed a systematic approach for CF calculation (CF-SA, figure 1), based on both the ISO 14067-2018 standard ${ }^{4}$ and guideline 'Greenhouse Gas Accounting Sector Guidance for Pharmaceutical Products and Medical Devices' released for the pharmaceutical sector by NHS in UK, ${ }^{5}$ which facilitates the calculation of the $\mathrm{CF}$ of multiple products within the same organisation, as long as they have the same scope, in terms of datasets and allocation modes. The purpose of the CF-SA is the creation of a certified system through which an organisation can independently create and register the $\mathrm{CF}$ of products, without the need to certify the individual $\mathrm{CF}$ from time to time by a third party. The CF-SA also allows the assessment of the $\mathrm{CF}$ of products already in the development phase, supporting appropriate design considering also environmental impact. We calculated and certified through a third party the $\mathrm{CF}$ of MDI and DPI products manufactured by Chiesi Farmaceutici SpA, including: Clenil 


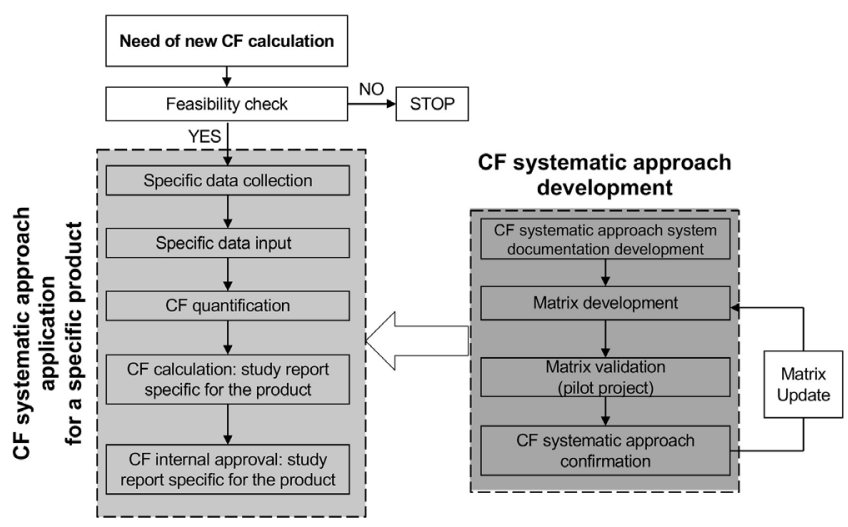

Figure 1 Flowchart describing the systematic approach for CF calculation. The section on the right specifically describes the development of the systematic approach system, including the development and validation of the calculation model (the matrix). The section on the left describes the application of the system to a specific product including all the steps for calculation and approval. CF, carbon footprint.

(beclometasone dipropionate) MDI, Foster (extrafine beclometasone/formoterol) MDI and Foster NEXThaler DPI, Trimbow (extrafine beclometasone/formoterol/ glycopyrronium) MDI. Notably, the propellant used for all these MDI products is HFA134a; among the currently available HFA propellants for pharmaceutical use, HFA134a has a substantially lower GWP as compared with HFA227 ea ${ }^{1}$ which has been deployed in other MDI products. In addition, the $\mathrm{CF}$ was calculated for the same MDI products when manufactured with HFA152a, considered as a candidate to replace HFA134a to reduce the environmental impact, due to its 10-times lower CF. ${ }^{6}$

\section{RESULTS}

The $\mathrm{CF}$ for the selected MDI products ranges from 82 to $119 \mathrm{gCO}_{2} \mathrm{e} /$ actuation, rounded (table 1) while for DPIs it is $8 \mathrm{gCO}_{2} \mathrm{eq} /$ actuation, rounded.

As reported for other products, a higher CF for MDIs is related to the propellant, with the majority of $\mathrm{CO}_{2} \mathrm{e}$ emissions arising from the use phase and disposal, while for DPIs, primary contributors are represented by the device components/packaging and production phase. ${ }^{78}$ Detailed analysis of the contribution to their individual $\mathrm{CF}$ of the different phases in the life cycle (from the 'cradle to the grave') of one MDI and one DPI product is reported in table 2 .

Since the greater contribution to the MDI products footprint occurs when patients use the device, the greater reduction of the total $\mathrm{CF}$ can be achieved by reformulating the products using a low GWP propellant. Indeed, with the systematic approach, we were able to estimate the $\mathrm{CF}$ of the same products if formulated with HFA152a and were able to confirm a significant reduction by approximately $85 \%-90 \%$ (table 1 ), and to within the range of CF values for DPIs ${ }^{39}$ and consistent with published CF values from studies testing only the propellant. ${ }^{6}$ In terms of applicability of HFA152a for medical use, recently presented data and UN publications report that the propellant has shown some promising MDI formulation benefits in initial research. ${ }^{3}$ The toxicology of HFA152a

Table $1 \mathrm{CF}\left(\mathrm{gCO}_{2} \mathrm{e}\right)$ value of specific MDI products, containing HFA134a propellant, CF estimation of the same products if formulated with a low GWP propellant (HFA152a) ${ }^{1}$ and CF of specific DPI products

\begin{tabular}{|c|c|c|c|c|c|}
\hline \multirow[b]{2}{*}{ Product name (INN) } & \multirow[b]{2}{*}{$\begin{array}{l}\text { Strength } \\
(\mu \mathrm{g} / \text { actuation })\end{array}$} & \multirow[b]{2}{*}{$\begin{array}{l}\text { Type of } \\
\text { device }\end{array}$} & \multirow[b]{2}{*}{$\begin{array}{l}\text { Actuations } \\
\text { per inhaler }\end{array}$} & \multicolumn{2}{|c|}{$\mathrm{CF}\left(\mathrm{gCO}_{2} \mathrm{e} /\right.$ actuation) } \\
\hline & & & & $\begin{array}{l}\text { With } \\
\text { HFA134a } \\
\text { (certified) }\end{array}$ & $\begin{array}{l}\text { With HFA152a } \\
\text { (estimated) }\end{array}$ \\
\hline $\begin{array}{l}\text { Clenil } \\
\text { (beclometasone dipropionate) }\end{array}$ & 100 & MDI & 200 & 83.10 & 9.39 \\
\hline $\begin{array}{l}\text { Clenil } \\
\text { (beclometasone dipropionate) }\end{array}$ & 200 & MDI & 200 & 81.96 & 9.31 \\
\hline $\begin{array}{l}\text { Foster } \\
\text { (beclometasone dipropionate/formoterol) }\end{array}$ & $100 / 6$ & MDI & 120 & 94.42 & 12.10 \\
\hline $\begin{array}{l}\text { Foster } \\
\text { (beclometasone dipropionate/formoterol) }\end{array}$ & $200 / 6$ & MDI & 120 & 118.56 & 14.05 \\
\hline $\begin{array}{l}\text { Foster NEXThaler } \\
\text { (beclometasone dipropionate/formoterol) }\end{array}$ & $100 / 6$ & DPI & 120 & 7.63 & Not applicable \\
\hline $\begin{array}{l}\text { Foster NEXThaler } \\
\text { (beclometasone dipropionate/formoterol) }\end{array}$ & $200 / 6$ & DPI & 120 & 7.64 & Not applicable \\
\hline $\begin{array}{l}\text { Trimbow } \\
\text { (beclometasone dipropionate/formoterol/glycopyrronium) }\end{array}$ & $87 / 5 / 9^{*}$ & MDI & 120 & 118.99 & 14.34 \\
\hline
\end{tabular}

HFA134a, 1,1,1,2-tetrafluoroethane (GWP value 1300'1); HFA152a 1,1-difluoroethane (GWP value 1381).

${ }^{*}$ Delivered dose.

CF, carbon footprint; DPI, dry powder inhaler; GWP, global warming potential; HFA, hydrofluoroalkane; INN, International Nonproprietary Names; MDI, metered dose inhaler. 
Table 2 Contribution of phases in the life cycle, from 'cradle to grave', of Foster 100/6 $\mu \mathrm{g}$ MDI 120 doses and Foster NEXThaler DPI 100/6 $\mu \mathrm{g} 120$ doses, to their individual carbon footprint for single actuation ( $\mathrm{gCO}_{2} \mathrm{e} /$ actuation) and their relative contribute (\%)

\begin{tabular}{|c|c|c|c|c|c|}
\hline \multicolumn{2}{|c|}{ Product name (INN) } & \multicolumn{2}{|c|}{$\begin{array}{l}\text { Foster } 100 / 6 \mu \mathrm{g} \text { MDI } \\
120 \text { doses }\end{array}$} & \multicolumn{2}{|c|}{$\begin{array}{l}\text { Foster NEXThaler } 100 / 6 \mu \mathrm{g} \mathrm{DPI} \\
120 \text { doses }\end{array}$} \\
\hline Life cycle stac & 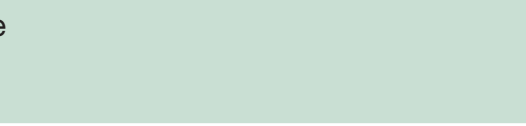 & $\begin{array}{l}\text { Absolute } \\
\text { contribute } \mathrm{gCO}_{2} \mathrm{e} / \\
\text { actuation }\end{array}$ & $\begin{array}{l}\text { Relative } \\
\text { contribute } \\
\%\end{array}$ & $\begin{array}{l}\text { Absolute } \\
\text { contribute } \mathrm{gCO}_{2} \mathrm{e} / \\
\text { actuation }\end{array}$ & $\begin{array}{l}\text { Relative } \\
\text { contribute } \\
\%\end{array}$ \\
\hline \multirow[t]{4}{*}{ Upstream } & $\begin{array}{l}\text { Raw materials-active } \\
\text { pharmaceutical ingredients and } \\
\text { excipients }^{\star}\end{array}$ & 1.29 & 1.36 & 0.02 & 0.24 \\
\hline & Raw materials-device components & 0.81 & 0.85 & 1.60 & 21.02 \\
\hline & $\begin{array}{l}\text { Raw materials-packaging } \\
\text { components }\end{array}$ & 0.12 & 0.13 & 0.33 & 4.37 \\
\hline & $\begin{array}{l}\text { Supplementary materials-device } \\
\text { packaging }\end{array}$ & 0.96 & 1.02 & 2.46 & 32.20 \\
\hline Total & & $\begin{array}{l}3.18 \mathrm{gCO}_{2} \mathrm{e} / \\
\text { actuation }\end{array}$ & $3.37 \%$ & $\begin{array}{l}4.41 \mathrm{gCO}_{2} \mathrm{e} / \\
\text { actuation }\end{array}$ & $57.83 \%$ \\
\hline \multirow[t]{4}{*}{ CORE } & Raw materials transportation & 0.10 & 0.11 & 0.14 & 1.89 \\
\hline & Energy and water consumption & 2.00 & 2.12 & 1.96 & 25.72 \\
\hline & Manufacturing waste & 0.07 & 0.08 & 0.07 & 0.94 \\
\hline & HFA leaks and air emissions & 1.43 & 1.51 & 0.00 & 0.00 \\
\hline Total & & $\begin{array}{l}3.60 \mathrm{gCO}_{2} \mathrm{e} / \\
\text { actuation }\end{array}$ & $3.82 \%$ & $\begin{array}{l}2.18 \mathrm{gCO}_{2} \mathrm{e} / \\
\text { actuation }\end{array}$ & $28.54 \%$ \\
\hline \multirow[t]{3}{*}{ Downstream } & Distribution and transportation & 0.33 & 0.35 & 0.33 & 4.29 \\
\hline & User phase & 66.27 & 70.19 & 0.00 & 0.00 \\
\hline & End of life & 21.04 & 22.28 & 0.71 & 9.34 \\
\hline \multicolumn{2}{|l|}{ Total } & $\begin{array}{l}87.64 \mathrm{gCO}_{2} \mathrm{e} / \\
\text { actuation }\end{array}$ & $92.82 \%$ & $\begin{array}{l}1.04 \mathrm{gCO}_{2} \mathrm{e} / \\
\text { actuation }\end{array}$ & $13.63 \%$ \\
\hline \multicolumn{2}{|c|}{ Total CF gCO ${ }_{2} \mathrm{e} /$ actuation } & 94.42 & & 7.63 & \\
\hline
\end{tabular}

Data calculated using the CF-SA method.

*Excipients including propellant gas HFA134a in case of Foster 100/6 MDI.

CF, carbon footprint; CF-SA, systematic approach for CF calculation; DPI, Dry Powder Inhaler; HFA, hydrofluoroalkane; INN, International Nonproprietary Names ; MDI, metered-dose inhaler.

is well known as an industrial gas (similar to HFA134a). Work to fill in gaps in the industrial toxicity was initiated in 2016. ${ }^{3}$ The long-term toxicology testing on HFA152a is expected to be completed in 2021 with the first clinical trials in humans starting now. ${ }^{3}{ }^{10}$ Research and development on a range of HFA152a MDI drug formulations is underway, with similar performance to current HFA134a and HFA227ea MDIs. ${ }^{3}$

CF data obtained using the systematic approach can be compared with CF standard data reported per dose in official documents for inhalers and other commonly used products (figure 2).

\section{DISCUSSION}

To our knowledge, this is the first study evaluating these specific MDI and DPI products by using the systematic approach for the CF certification. For MDI, values of $\mathrm{gCO}_{2} \mathrm{e}$ per dose (two actuations) range from 164 to 238. The calculated values are lower, or in the lower range, compared with what has been reported in recent publications $^{11}$ and much lower compared with the value reported in the NICE Patient decision aid. ${ }^{9}$ Despite the very limited contribution of HFAs in pharmaceutical use to the total HFA emissions, a structured approach should be adopted to move to more sustainable solutions to treat respiratory diseases. Recent articles suggest that a way of reducing the environmental impact of MDIs is represented by a switch to alternative devices like DPIs, which do not contain propellant. ${ }^{711}$

Published data based on the analysis of a sales database in Europe indicated that a high proportion of patients tend to rely on the use of a MDI, ${ }^{12}$ with the majority of MDI sold being reliever therapies and this is suggested to also be the case globally. ${ }^{3}$ The wide use of MDI therapies can be linked, at least for reliever therapies, to a lower average cost. However, a proportion of patients rely on using MDIs reliever and/or maintenance products to manage their condition, being familiar with this kind of 


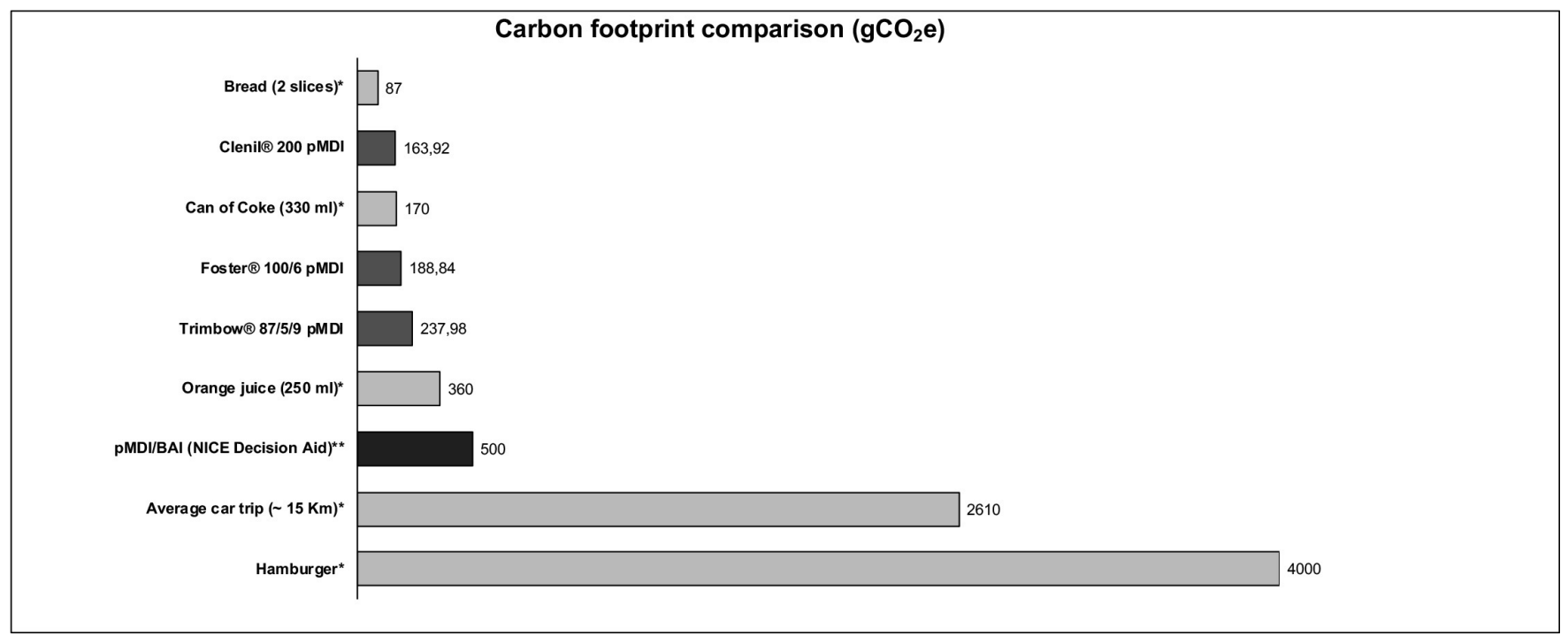

Figure 2 CF data for specific MDI products, compared with standard data reported for commonly used products (*) ${ }^{3}$ and in official documents $\left(^{*}\right) .{ }^{9}$ Data for inhaled products are reported per dose, equal to two actuations. BAl, breath-actuated inhaler; CF, carbon footprint; MDI, metered-dose inhaler.

device as reliever. ${ }^{13}$ Patients also benefit from the use of MDIs because this allows them to use spacers which are deemed important to support optimal drug delivery for some patients. ${ }^{14}$ The Global Initiative for Asthma $(\mathrm{GINA})^{15}$ report indicates MDI with a spacer device as the preferred option for patients, like children or the elderly, who are unable to generate the required level of inspiratory flow or struggle to use some DPIs due to device handling errors. ${ }^{1316}$

The optimal choice of the most suitable inhaled therapy is therefore a complex decision taken between healthcare professional and patient. Switching inhalers can be considered safe, if implemented correctly, which should include appropriate patient selection and mandating the importance of providing inhaler education. ${ }^{17}$ However, other papers report that non-consensual switches can result in patient discontent, reduced confidence in the medication, and uncertainty regarding the degree of disease control and therefore it is recommended that patients with stable disease remain on their current device. $^{18}$

Approaches to more sustainable solutions should therefore effectively balance environmental goals with patient health while maintaining a diverse range of therapeutic choices which allow patients and healthcare professionals to select the most appropriate medicationdevice combination. In the short term, actions can be taken to reduce inappropriate use and waste, such as better training and education for physicians and patients and improved disposal and recycling of used inhalers. ${ }^{16}$ Moreover, the experience of the CFC to HFA transition testifies that innovation, meaning investing in the development of new sustainable products, may offer environmental benefits beyond other actions, such as switching to DPI. With the model used in the present study, an $85 \%-90 \%$ reduction in the CF of existing MDIs if transitioned to new propellants is envisaged. Indeed, development programmes of environmentally-friendly MDIs using low GWP propellants by 2025 have been announced. ${ }^{19} 20$ Therefore, restrictive and short-term device switching approaches risk to undermine the innovation around low GWP inhalers, missing the opportunity of a major environmental driver and preventing groups of patients to access the appropriate solutions that they need for the optimal continuity of their care.

In conclusion, the present study demonstrated that the $\mathrm{CF}$ of a specific series of MDI products is in the lower range or lower compared with what has been reported, ${ }^{911}$ underlining the need for proper quantification. Moreover, that the environmental impact may be significantly reduced through deployment of new MDI propellants. Such investments in research and innovation should be the way forward to find 'green' alternatives while preserving patient-tailored treatment in terms of inhaler choice.

Contributors The authors declare the following contributions to this study: all authors contributed to drafting and finalising the manuscript and approved the final version for submission. SP is the guarantor, taking responsibility for work and/or conduct of study, full access to data and control of decision to publish.

Funding The authors have not declared a specific grant for this research from any funding agency in the public, commercial or not-for-profit sectors.

Competing interests All authors are Chiesi Farmaceutici SpA employees.

Patient consent for publication Not required.

Provenance and peer review Not commissioned; externally peer reviewed.

Open access This is an open access article distributed in accordance with the Creative Commons Attribution Non Commercial (CC BY-NC 4.0) license, which permits others to distribute, remix, adapt, build upon this work non-commercially, and license their derivative works on different terms, provided the original work is properly cited, appropriate credit is given, any changes made indicated, and the use is non-commercial. See: http://creativecommons.org/licenses/by-nc/4.0/. 


\section{REFERENCES}

1 IPCC fifth assessment report (AR5), 2014. Available: https://www. ipcc.ch/report/ar5/syr/ [Accessed 21 Nov 2019].

2 European environment agency, fluorinated greenhouse gases, 2018. Available: https://www.eea.europa.eu/publications/fluorinatedgreenhouse-gases-2018/ [Accessed Dec 2019].

3 United Nations. Montreal protocol on substances that deplete the ozone layer. 2018 report of the medical and chemical technical options Committee (MCTOC), 2018. Available: https://ozone.unep. org/sites/default/files/2019-04/MCTOC-Assessment-Report-2018. pdf [Accessed 21 Nov 2019].

4 Iso 14067:2018 greenhouse gases - carbon footprint of products - requirements and guidelines for quantification. Available: https:// www.iso.org/standard/71206.html [Accessed 4 Mar 2020].

5 Greenhouse gas accounting sector guidance for pharmaceutical products and medical devices, NHS sustainable development units, 2012. Available: https://ghgprotocol.org/sites/default/files/SummaryDocument_Pharmaceutical-Product-and-Medical-Device-GHGAccounting_November-2012_0.pdf [Accessed 4 Mar 2020].

6 Jeswani HK, Azapagic A. Life cycle environmental impacts of inhalers. J Clean Prod 2019;237:117733.

7 Janson C, Henderson R, Löfdahl M, et al. Carbon footprint impact of the choice of inhalers for asthma and COPD. Thorax 2020;75:82-4.

8 Janson C, Henderson R, Löfdahl M, et al. Carbon footprint impact of the choice of inhalers for asthma and COPD. Thorax 2020;75:82-4.

9 National Institute for health and care excellence (NICE), patient decision aid, inhalers for asthma, 2019. Available: https://www. nice.org.uk/guidance/ng80/resources/inhalers-for-asthma-patientdecision-aid-pdf-6727144573 [Accessed 21 Nov 2019].

10 Green' medical Propellant receives FDA approval to proceed to clinical trials, CISION PR Newswire, 2020. Available: https:// www.prnewswire.com/news-releases/green-medical-propellantreceives-fda-approval-to-proceed-to-clinical-trials-300998598.html [Accessed 4 Mar 2020].
11 Wilkinson AJK, Braggins R, Steinbach I, et al. Costs of switching to low global warming potential inhalers. An economic and carbon footprint analysis of NHS prescription data in England. BMJ Open 2019;9:e028763.

12 Lavorini F, Corrigan CJ, Barnes PJ, et al. Retail sales of inhalation devices in European countries: so much for a global policy. Respir Med 2011;105:1099-103.

13 Kaplan A, Price D. Matching inhaler devices with patients: the role of the primary care physician. Can Respir J 2018;2018:1-9.

14 Vincken W, Levy ML, Scullion J, et al. Spacer devices for inhaled therapy: why use them, and how? ERJ Open Res 2018;4:000652018-2018.

15 The global strategy for asthma management and prevention, global initiative for asthma (GINA), 2019. Available: https://ginasthma.org/ [Accessed 4 Mar 2020].

16 Usmani OS, Scullion J, Keeley D. Our planet or our patientsis the sky the limit for inhaler choice? The Lancet Respir. Med 2019;7:11-13.

17 Bloom Cl, Douglas I, Olney J, et al. Cost saving of switching to equivalent inhalers and its effect on health outcomes. Thorax 2019;74:1078-86.

18 Bjermer L. The importance of continuity in inhaler device choice for asthma and chronic obstructive pulmonary disease. Respiration 2014:88:346-52.

19 Chiesi outlines $€ 350$ million investment and announces first carbon minimal pressurised metered dose inhaler (pMDI) for asthma and COPD, 04 Dec 2019. Available: https://www.chiesi.com/en/chiesioutlines-350-million-investment-and-announces-first-carbonminimal-pressurised-metered-dose-inhaler-pmdi-for-asthma-andcopd/ [Accessed 4 Mar 2020].

20 Investing in a sustainable future for patients with respiratory disease, 2020. Available: https://www.astrazeneca.com/content/astraz/ media-centre/articles/2020/investing-in-a-sustainable-future-forpatients-with-respiratory-disease.html [Accessed 4 Mar 2020]. 